\title{
High Prevalence of Triple-Negative Breast Cancer in Southern Shaanxi Province, China
}

This article was published in the following Dove Press journal:

Cancer Management and Research

\author{
Xuemei Xing ${ }^{1, *}$ \\ Zhigang Fan ${ }^{2, *}$ \\ Yue $\mathrm{Gao}^{3}$ \\ Zheng Liu' ${ }^{1,3}$ \\ 'Department of Clinical Laboratory, 320 I \\ Hospital, Xi'an Jiaotong University Health \\ Science Center, Hanzhong, Shaanxi, \\ 723000, People's Republic of China; \\ ${ }^{2}$ Department of Oncology, 320I \\ Hospital, Xi'an Jiaotong University Health \\ Science Center, Hanzhong, Shaanxi, \\ 723000, People's Republic of China; \\ ${ }^{3}$ College of Medical Laboratory Science, \\ Guilin Medical University, Guilin, \\ Guangxi, 541004, People's Republic of \\ China
}

*These authors contributed equally to this work
Correspondence: Zheng Liu

Department of Clinical Laboratory, 320I

Hospital, Xi'an Jiaotong University Health

Science Center, 783 Tianhan Ave,

Hanzhong, Shaanxi, 723000, People's

Republic of China

$\mathrm{Tel} / \mathrm{Fax}+869162383201$

Email zliuIIII@I63.com
Purpose: Describing the clinical features of patients with breast cancer in an area is important to provide the information for the local oncologist to make sound treatment plans. In this study, we explored the clinical features of breast cancer patients in Southern Shaanxi Province, China.

Patients and Methods: A total of 328 breast cancer patients between 2010 and 2015 were recruited at our hospital. Patients' clinical information and the results of the histopathological examination were collected. Independent sample $t$-test and Cox regression were used to analyze the data.

Results: The peak age onset of these patients was between 45 and 50. At diagnosis, 8.23\% of patients were at clinical stage 1 and $29.57 \%$ were triple-negative breast cancer subtype. High expression of $\mathrm{Ki}-67$ in these patients was found associated with triple-negative breast cancer. The 5 -year survival rate in these patients was $66.4 \%$, and the survival rate in stage 1 and 2 patients $(88.2 \%)$ was significantly higher than that in stage 3 and $4(57.4 \%)$.

Conclusion: We here reported the clinical features of patients with breast cancer in Southern Shaanxi Province, China. The breast cancer patients in Southern Shaanxi Province showed a unique clinical feature.

Keywords: 5-year survival rate, breast cancer, clinical features, triple-negative breast cancer

\section{Introduction}

Breast cancer is one of the most common cancers in women worldwide, and it is the leading cause of death in both developed and developing countries. ${ }^{1}$ Although the incidence rate of breast cancer is lower in Asian population compared with other races, there is an increasing trend in China over the past two decades. ${ }^{2}$ Environmental pollution is considered to be one of the main causes of breast cancer. ${ }^{3}$ Metals are ubiquitous in the environment from natural sources, industry, and fossil fuel combustion. ${ }^{4}$ Some metals, including mercury, cadmium, and lead have been judged carcinogenic in humans by the International Agency for Research on Cancer, but the mechanism of these chemicals causing breast cancer is unclear. ${ }^{5}$ One explanation is that these chemicals are traditionally defined as carcinogens, and some of them fall into the class of endocrine-disrupting compounds. ${ }^{6}$

In recent years, several biomarkers including estrogen receptor (ER), progesterone receptor (PR), human epidermal growth factor receptor-2 (HER2), and proliferation marker $\mathrm{Ki}-67$ have been used for prediction and treatment guidance of breast cancer. ${ }^{7}$ Usually, ER-positive patients will benefit from hormonal therapy. Overexpression of HER2 is associated with more aggressive tumor type and poor 
clinical outcome. ${ }^{8} \mathrm{Ki}-67$ is a nuclear protein associated with cell proliferation and used as a prognostic marker in many malignant tumors including breast cancer. ${ }^{9}$

Breast cancer can be divided into triple-negative breast cancer (TNBC) and non-TNBC. TNBC is defined by the lack of expression of hormone receptors (ER and PR) and low expression of HER2, and do not respond to hormonal or anti-HER2 therapies. ${ }^{10}$ Therefore, reporting the prevalence of breast cancer subtypes in an area will guide local oncologists to make an efficient treatment plan. In this study, we collected and analyzed the data of 328 breast cancer patients from Southern Shaanxi province, China, and reported the clinical feature of these breast cancer patients.

\section{Patients and Methods}

\section{Patients}

This retrospective study was conducted from 2010 to 2015 at 3201 hospital, Xi' an Jiaotong University Health Science Center, in Southern Shaanxi Province. A total of 328 patients were recruited. The medical information including age, tumor position, expression of ER and PR, expression of Ki-67, HER2 status and disease stage at diagnosis, etc. were recorded. Eighty-nine patients have available information of survival time during the follow-up. The study was approved by the Institutional Review Board of 3201 hospital. The informed consent was obtained from all patients. The procedures performed in this study involving human participants were in accordance with the Helsinki Declaration of 1975, as revised in 2008.

\section{Histopathological Examination}

The patients were grouped into four subtypes based on the expression of genetic markers. Tumor phenotypes were categorized as luminal A (ER+ and/or PR+/HER2-), luminal B (ER+ and/or PR+/HER2+), triple-negative (ER- and PR-/HER2-), and basal-like (ER-/PR-/HER2+). The patients were also divided into two groups with a commonly used Ki-67 expression value of $20 \%$ as the cutoff. Breast cancer is designated as T4d in the American Joint Committee on Cancer Tumor, Node, Metastasis (TNM) staging system as previously described. ${ }^{11}$

Patients were examined at our hospital and the clinical characteristics including histology information, tumor size, axillary lymph node metastasis, pathological tumor-nodemetastasis staging, ER, PR, HER-2 status, and Ki-67 expression level were collected. Tumor specimens were processed within 30 minutes from surgery for pathology testing. Tumor tissues were fixed in $10 \%$ neutral formaldehyde for $6 \sim 48$ hours, and then embedded in paraffin and cut into $5 \mu \mathrm{m}$ slices. Tumors were graded as 1,2 , and 3 based on the information of three parameters: the formation of nuclear pleomorphism, the formation of tubules, and the number of mitoses. The scores from the three parameters were summed up and ranged from 3 to 9: 3-5 for grade 1 with well-differentiated tumor; $6-7$ for grade 2 with moderately differentiated tumor; and $8-9$ for grade 3 with the poorly differentiated tumor. HER-2 status was decided by immunohistochemistry staining, scores 0 and 1 were considered as negative, 2 and 3 were considered as positive. For ER and PR scoring, the breast cancer specimens with $>1 \%$ positively staining cells by immunohistochemistry were considered ER or PR positive. Ki-67 proliferation level was determined by the percentage of positive cells among the tested cells. For each patient, the pathological testing results were reviewed by two qualified pathologists for interpretation and diagnosis.

\section{Treatment}

The treatment methods include surgical resection, chemotherapy, radiotherapy, and endocrine therapy. Most of the time, the treatment plan is the result of communication between doctors and patients based on the development of the tumor, the patient's economy, and the patient's reasons.

\section{Statistical Analysis}

Data are reported as the mean $\pm \mathrm{SD}$. An independent sample $t$-test was used to assess the difference between different disease subtypes. Cox regression was used for survival analysis. $\mathrm{R}$ version 3.0 .2 was used for all the statistical analyses in this study.

\section{Results}

\section{The Characteristics of Patients}

The average age of the breast cancer patients is 50.49 in this study. Of the patients, $85.64 \%$ have an age-onset between 35 and 65 years old, and the peak age of breast cancer is from 45 to 50 years old (Table 1). The histopathology classification showed about 97 (29.57\%) breast cancer patients are TNBC subtype, followed by luminal B subtype (32.01\%). Luminal A and HER2 positive subtypes share the rest of the patients. Of the patients, $40.24 \%$ were at T1 stage. Of the patients, $32.93 \%$ were at T2 stage. $15.55 \%$ and $11.28 \%$ of the patients were at $\mathrm{T} 3$ and $\mathrm{T} 4$, 
Table I Demographic Characteristics of Breast Cancer Patients Included in Study

\begin{tabular}{|l|c|}
\hline Variables & Number (\%) \\
\hline Age & $50.49 \pm 10.55$ \\
\hline Tumor location & $173(52.74)$ \\
\hline Left & $155(47.26)$ \\
Right & \\
\hline Clinical stage & $27(8.23)$ \\
\hline I & $196(59.76)$ \\
2 & $93(28.35)$ \\
3 & $12(3.66)$ \\
4 & \\
\hline Molecular subtype & $87(26.52)$ \\
\hline Luminal A & $105(32.01)$ \\
Luminal B & $97(29.57)$ \\
Triple negative & $39(11.89)$ \\
HER2 type & $148(40.55)$ \\
\hline T stage & $119(32.60)$ \\
\hline TI & $22(6.02)$ \\
T2 & $108(32.93)$ \\
T3 & $57(11.55)$ \\
T4 & \\
\hline N stage & \\
\hline No & \\
NI & \\
N2 & \\
N3 & \\
\hline
\end{tabular}

respectively. One hundred and forty-eight patients were at N0, 119 patients at N1, 76 and 22 patients were at $\mathrm{N} 2$ and N3, respectively (Table 1).

\section{Clinical Characteristics and Breast Cancer Subtypes}

We further tested the relationship between clinical characteristics and breast cancer subtypes. There were 159 and 169 patients in age-onset " $<50$ " and " $\geq 50$ " groups. Of the patients, $23.27 \%$ and $55.97 \%$ were Luminal B and TNBC subtype in the " $<50$ " group, compared with $10.65 \%$ and $69.82 \%$ for the two subtypes in the " $\geq 50$ " group (Table 2 ). The results showed there was a significant difference in subtypes distribution between the early and late age-onset group $(P$ value $=0.012)$. The average value of Ki-67 expression among the patients was $45.11 \pm 25.90 \%$ (range $1-90 \%$ ).
Of the patients, $61.05 \%$ and $11.58 \%$ in the low $\mathrm{Ki}-67$ expression group are luminal A and luminal B, respectively. Of the patients, $21.05 \%$ are triple-negative and $7.22 \%$ for HER2 type. In high Ki-67 expression group, only $19.31 \%$ of the patients are luminal subtype and $76.82 \%$ for triplenegative, and 3.86\% for HER2 type (Table 2). The statistical test produced a $P$ value less than $2.1 \times 10^{-15}$, which displayed a strong association between $\mathrm{Ki}-67$ expression level and breast cancer subtypes. We also detected an association between $\mathrm{T}$ stage and breast cancer subtype $(P$ value $=0.008)$.

\section{The Correlation Between ER/PR Status and Ki-67 Expression Level}

We further studied the correlation between ER/PR status and Ki-67 expression level as ER/PR status was important prognostic marker in breast cancer subtype classification. Ninety-seven patients were ER+ and/or PR+ group and 206 patients in ER-/PR-group (Table 3). The average Ki67 expression value in ER+ and/or PR+ group was 19.48\% and $57.38 \%$ in ER-/PR-group (Table 3). There was a significant difference in $\mathrm{Ki}-67$ expression between ER+ and/or PR+ and ER-/PR-group $\left(P\right.$ value $<2 \mathrm{e}^{-16}$ ). This result suggested a strong relationship between the level of Ki-67 expression and ER/PR status.

\section{The Correlation Between HER2 and ER/ PR Status}

HER2 and ER, PR are all important prognostic markers for breast cancer diagnosis. We investigated the correlation between HER2 and ER/PR status. Eighteen patients were HER2 positive and 310 were HER2 negative. Among the patients with HER 2 negativity status, $66.2 \%$ of them were ERnegative and $71.9 \%$ of them were PR negative. There was a strong correlation between HER2 negativity and ER/PR negativity. The statistical test produced a $P$ value of $1.80 \times 10^{-4}$ (Table 4).

\section{The Treatment and 5-Year Survival Rate}

In Table 5, most patients received radical mastectomy (94.10\%). Of the patients, $74.72 \%$ and $34.95 \%$ received chemotherapy and radiotherapy. Of patients, 29.48\% received endocrine therapy for 2-5 years when their positive expression of ER was $>5 \%$. The 5-year survival rate in breast cancer patients is $66.4 \%(95 \% \mathrm{CI}=(0.924,1.00))$. We further stratified the patients into stage 1 and 2 and stage 3 and 4. Five-year survival rate in stage 1 and 2 patients was $88.2 \%$ $(95 \% \mathrm{CI}=(0.95,1.00))$ and $57.4 \%(95 \% \mathrm{CI}=(0.77,1.00))$ in 
Table 2 Breast Cancer Subtypes in Our Patients

\begin{tabular}{|c|c|c|c|c|c|c|}
\hline Features & Total & $\begin{array}{l}\text { Luminal A Number } \\
\text { (\%) }\end{array}$ & $\begin{array}{l}\text { Luminal B Number } \\
\text { (\%) }\end{array}$ & $\begin{array}{c}\text { Triple Negative Number } \\
(\%)\end{array}$ & $\begin{array}{c}\text { HER2 Type Number } \\
\text { (\%) }\end{array}$ & $P$ value \\
\hline \multicolumn{6}{|l|}{ Age } & \multirow[t]{3}{*}{0.012} \\
\hline$<50$ & 159 & $25(15.72)$ & 37 (23.27) & 89 (55.97) & $8(5.03)$ & \\
\hline$\geq 50$ & 169 & $22(13.02)$ & $18(10.65)$ & II8 (69.82) & II (6.5I) & \\
\hline \multicolumn{6}{|c|}{ Ki-67 expression } & \multirow[t]{3}{*}{$<2.1 \times 10^{-15}$} \\
\hline$<20 \%$ & 95 & $58(61.05)$ & II (II.58) & $20(21.05)$ & $6(7.22)$ & \\
\hline$\geq 20 \%$ & 233 & $0(0)$ & $45(19.31)$ & I79 (76.82) & $9(3.86)$ & \\
\hline \multicolumn{6}{|c|}{ Clinical stage } & \multirow[t]{5}{*}{0.046} \\
\hline I & 27 & $9(33.33)$ & 3 (II.II) & $13(48.15)$ & $2(7.4 I)$ & \\
\hline II & 196 & $25(12.76)$ & 28 (14.29) & $132(67.35)$ & II (5.6I) & \\
\hline III & 93 & $10(10.75)$ & $19(20.43)$ & $59(63.44)$ & $5(5.37)$ & \\
\hline IV & 12 & $3(25.00)$ & $5(41.67)$ & $3(25.00)$ & I (8.33) & \\
\hline \multicolumn{6}{|l|}{ T stage } & \multirow[t]{5}{*}{0.008} \\
\hline I & 45 & $12(26.67)$ & $3(6.67)$ & $27(60.00)$ & $3(6.67)$ & \\
\hline 2 & 229 & $31(13.54)$ & $36(15.72)$ & $15 \mid(65.94)$ & II (4.80) & \\
\hline 3 & 44 & $2(9.52)$ & $12(27.27)$ & $27(6 \mid .36)$ & $3(6.81)$ & \\
\hline 4 & 10 & $2(20.00)$ & $4(40.00)$ & $2(20.00)$ & $2(20.00)$ & \\
\hline \multicolumn{6}{|l|}{ N stage } & \multirow[t]{5}{*}{0.084} \\
\hline 0 & 132 & $24(18.18)$ & $17(12.88)$ & $83(62.88)$ & $8(6.06)$ & \\
\hline I & 108 & II (10.19) & 15 (13.89) & 76 (70.37) & $6(5.56)$ & \\
\hline 2 & 51 & $10(19.60)$ & $14(27.44)$ & $25(49.02)$ & $2(3.91)$ & \\
\hline 3 & 37 & $4(10.8 I)$ & $8(21.62)$ & $16(43.24)$ & $9(24.33)$ & \\
\hline
\end{tabular}

Abbreviation: HER2, human epidermal growth factor receptor-2.

Table 3 Ki-67 Expression Between Groups

\begin{tabular}{|c|c|c|c|}
\hline Biomarkers & Number of Cases & Ki-67 Level (\%) (Mean士SD) & $P$-value \\
\hline $\mathrm{ER}+$ and/or PR+ & 97 & $19.48 \pm 17.48$ & $<2 \times 10^{-16}$ \\
\hline ER-/PR- & 206 & $57.38 \pm 19.42$ & \\
\hline HER2+ & 24 & $36.71 \pm 21.59$ & 0.098 \\
\hline HER2- & 280 & $45.83 \pm 26.15$ & \\
\hline
\end{tabular}

Abbreviations: ER, estrogen receptor; PR, progesterone receptor; HER2, human epidermal growth factor receptor-2.

Table 4 Correlation Between HER2 and ER/PR Status

\begin{tabular}{|l|c|c|c|c|}
\hline Biomarkers & Number of Cases & ER-Number (\%) & PR-Number (\%) & $P$-value \\
\hline HER2+ & 18 & & & \\
HER2- & 310 & $205(66.2 \%)$ & $222(71.9 \%)$ & $1.80 \times 10^{-4}$ \\
\hline
\end{tabular}

Abbreviations: ER, estrogen receptor; PR, progesterone receptor; HER2, human epidermal growth factor receptor-2. 
Table 5 The Treatment Methods and Plan for These Patients

\begin{tabular}{|c|c|c|}
\hline $\begin{array}{l}\text { Treatment } \\
\text { Methods }\end{array}$ & $\begin{array}{l}\text { Patients } \\
\text { (\%) }\end{array}$ & Treatment Plan \\
\hline \multicolumn{3}{|l|}{ Surgical resection } \\
\hline Only tumor resection & 2.13 & \\
\hline Radical mastectomy & 94.10 & \\
\hline $\begin{array}{l}\text { Breast-conserving } \\
\text { therapy }\end{array}$ & 3.76 & \\
\hline Chemotherapy & 74.72 & $\begin{array}{l}\text { Epirubicin } 50-70 \mathrm{mg} / \mathrm{m}^{2} \text { combined with cyclophosphamide } 400-600 \mathrm{mg} / \mathrm{m}^{2} \text { for } 3-4 \text { weeks, followed by } \\
\text { paclitaxel } 135-175 \mathrm{mg} / \mathrm{m}^{2}\end{array}$ \\
\hline Radiotherapy & 34.95 & $50-60 \mathrm{~Gy} / 25-30 \mathrm{f}$ \\
\hline Endocrine Therapy & 29.48 & $\begin{array}{l}\text { The patients were given tamoxifen or letrozole orally after chemoradiotherapy for } 2-5 \text { years when the } \\
\text { positive expression of ER was }>5 \%\end{array}$ \\
\hline
\end{tabular}

stage 3 and 4 patients. The survival curve between these two groups is significantly different $\left(P\right.$ value $\left.=3.84 \times 10^{-5}\right)$.

\section{Discussion}

TNBC usually accounts for $15-20 \%$ of breast cancer. ${ }^{12}$ It tends to more aggressive and is associated with a poor prognosis and high recurrence rate. ${ }^{13}$ In United States, TNBC could account for $39 \%$ of breast cancer cases in premenopausal African-American women. ${ }^{14}$ In Hong Kong and Southern China, only $13.4 \%$ of breast cancer patients was TNBC. ${ }^{15}$ A study from Shanghai showed that the prevalence of TNBC in breast cancer was $12.9 \%{ }^{16}$ These results indicate that the proportion of TNBC in different populations is very different. In our report, the result is quite different from other studies, and we found that a high proportion of patients was TNBC subtype in Southern Shaanxi province. Southern Shaanxi province is a special area in China. It is located in a relatively closed environment in Qinling Mountains. The previous report has shown that high soil selenium concentrations were found in this area where soil selenium concentrations could be $>20 \mathrm{mg} / \mathrm{kg} .{ }^{17}$ Some studies hypothesized that selenium deficiency may be associated with an increased risk of breast cancer. ${ }^{18}$ However, in the United States, the researchers found that selenium intake is not associated with incident breast cancer. ${ }^{19}$ These conflicting findings reveal that selenium plays a complex role in the development of breast cancer, showing that the relationship between selenium intake and the risk of breast cancer is unclear. Another report revealed that soil cadmium and mercury pollution was detected in the production of tea in Southern Shaanxi Province. ${ }^{20}$ Dietary mercury and cadmium were demonstrated to be associated with a higher risk of breast cancer. ${ }^{18,21}$ Methylmercury could promote breast cancer cell proliferation by stimulating estrogen. ${ }^{22}$ Similarly, cadmium also has been shown to demonstrate estrogen-like activity, which is known to increase breast cancer risk. ${ }^{23}$ Unfortunately, few studies have focused on the relationship between carcinogenic properties of these metals and TNBC subtype in breast cancer patients. The etiology of a high proportion of TNBC in breast cancer patients in Southern Shaanxi Province needs to be further investigated.

In this study, there was no difference in peak age of breast cancer between our patients and other regions of China. ${ }^{24}$ Early detection of breast cancer is very important for patients as treatment is often more effective at an early stage. Only $8.23 \%$ of the diagnosed patients are stage 1 in this study. Of the patients, $32.01 \%$ are stage 3 and 4 . This distribution of disease stage at initial diagnosis is similar to that $(13.5 \%)$ from Renmin Hospital in Wuhan, China. ${ }^{25}$ Compared with $78 \%$ of newly diagnosed cases were stage 1 in Japan, this number was very low in China, which suggested a lack of breast cancer early detection program in China. ${ }^{26}$ That was easy to understand that the 5-year overall survival rate in this study was $66.4 \%$, lower than $76.5 \%$ from China, $87.0 \%$ from Japan, and 88\% from the United States. $^{27}$ In our report, we detected a higher proportion of TNBC in Ki-67 expression. Ki-67 is a nuclear antigen present in fast proliferating cells that have been widely used in cancer diagnosis. ${ }^{28}$ Studies showed a high level of Ki-67 was associated with severity of tumor and poor prognosis in breast cancer and $\mathrm{Ki}-67$ could be used to 
indicate different prognosis and treatment in TNBC patients. $^{29}$

\section{Conclusion}

In conclusion, we here reported that $29.57 \%$ of the breast cancer patients in Southern Shaanxi Province were TNBC, which showed a unique clinical feature in these patients. Our study also provides evidence that the TNBC subtype was associated with high expression of Ki-67, which showed a similar pattern of clinical characteristics with other regions of China.

\section{Acknowledgments}

This work was supported by Key Research and Development Program of Shaanxi Province (2017ZDXM-SF-067), Natural Science Foundation of Guangxi Zhuang Autonomous Region (2018JJA140045/2018GXNSFAA281048) and Guangxi Science and Technology Base and Special Fund for Talents (2018AD19267/AD19110161).

\section{Disclosure}

The authors report no conflicts of interest in this work.

\section{References}

1. Tao Z, Shi A, Lu C, Song T, Zhang Z, Zhao J. Breast cancer: epidemiology and etiology. Cell Biochem Biophys. 2015;72 (2):333-338. doi:10.1007/s12013-014-0459-6

2. Wang F, Yu ZG. Current status of breast cancer prevention in China. Chronic Dis Transl Med. 2015;1(1):2-8. doi:10.1016/j. cdtm.2015.02.003

3. Koual M, Tomkiewicz C, Cano-Sancho G, Antignac JP, Bats AS, Coumoul X. Environmental chemicals, breast cancer progression and drug resistance. Environ Health. 2020;19(1):117. doi:10.1186/s12940020-00670-2

4. Hiatt RA, Brody JG. Environmental determinants of breast cancer. Annu Rev Public Health. 2018;39(1):113-133. doi:10.1146/annurevpublhealth-040617-014101

5. Hu A, Li L, Hu C, et al. Serum concentrations of 15 elements among helicobacter pylori-infected residents from Lujiang County with high gastric cancer risk in Eastern China. Biol Trace Elem Res. 2018;186 (1):21-30. doi:10.1007/s12011-018-1283-4

6. Gray JM, Rasanayagam S, Engel C, Rizzo J. State of the evidence 2017: an update on the connection between breast cancer and the environment. Environ Health. 2017;16:94.

7. Van Asten K, Slembrouck L, Olbrecht S, et al. Prognostic value of the progesterone receptor by subtype in patients with estrogen receptor-positive, HER2 negative breast cancer. Oncologist. 2019;24 (2):165-171. doi:10.1634/theoncologist.2018-0176

8. Hart CD, Migliaccio I, Malorni L, Guarducci C, Biganzoli L, Di Leo A. Challenges in the management of advanced, ER-positive, HER2-negative breast cancer. Nat Rev Clin Oncol. 2015;12 (9):541-552. doi:10.1038/nrclinonc.2015.99

9. Soliman NA, Yussif SM. Ki-67 as a prognostic marker according to breast cancer molecular subtype. Cancer Biol Med. 2016;13 (4):496-504. doi:10.20892/j.issn.2095-3941.2016.0066
10. Shi J, Liu F, Song Y. Progress: targeted therapy, immunotherapy, and new chemotherapy strategies in advanced triple-negative breast cancer. Cancer Manag Res. 2020;12:9375-9387. doi:10.2147/ CMAR.S272685

11. Sawaki M, Shien T, Iwata H. TNM classification of malignant tumors (breast cancer study group). Jpn J Clin Oncol. 2019;49(3):228-231. doi:10.1093/jjco/hyy 182

12. Nakai K, Hung MC, Yamaguchi H. A perspective on anti-EGFR therapies targeting triple-negative breast cancer. Am J Cancer Res. 2016;6(8):1609-1623.

13. Wahba HA, El-Hadaad HA. Current approaches in treatment of triple-negative breast cancer. Cancer Biol Med. 2015;12 (2):106-116. doi:10.7497/j.issn.2095-3941.2015.0030

14. Sturtz LA, Melley J, Mamula K, Shriver CD, Ellsworth RE. Outcome disparities in African American women with triple negative breast cancer: a comparison of epidemiological and molecular factors between African American and Caucasian women with triple negative breast cancer. BMC Cancer. 2014;14(1):62. doi:10.1186/14712407-14-62

15. Kwong A, Mang OW, Wong CH, Chau WW, Law SC. Hong Kong breast cancer research group. Breast cancer in Hong Kong, Southern China: the first population-based analysis of epidemiological characteristics, stage-specific, cancer-specific, and disease-free survival in breast cancer patients: 1997-2001. Ann Surg Oncol. 2011;18 (11):3072-3078. doi:10.1245/s10434-011-1960-4

16. Su Y, Zheng Y, Zheng W, et al. Distinct distribution and prognostic significance of molecular subtypes of breast cancer in Chinese women: a population-based cohort study. BMC Cancer. 2011;11 (1):292. doi:10.1186/1471-2407-11-292

17. Du Y, Luo K, Ni R, Hussain R. Selenium and hazardous elements distribution in plant-soil-water system and human health risk assessment of Lower Cambrian, Southern Shaanxi, China. Environ Geochem Health. 2018;40(5):2049-2069. doi:10.1007/s10653-018$0082-3$

18. Cann SA, van Netten JP, van Netten C. Hypothesis: iodine, selenium and the development of breast cancer. Cancer Causes Control. 2000;11(2):121-127. doi:10.1023/A:1008925301459

19. Guo D, Hendryx M, Liang X, et al. Association between selenium intake and breast cancer risk: results from the women's health initiative. Breast Cancer Res Treat. 2020;183(1):217-226. doi:10.1007/ s10549-020-05764-6

20. Zhao ZP, Yan S, Duan M, et al. Assessing heavy metal pollution and potential ecological risk of tea plantation soils. Int J Agric Biol Eng. 2019;12:185-191.

21. Peng L, Huang Y, Zhang J, et al. Cadmium exposure and the risk of breast cancer in Chaoshan population of southeast China. Environ Sci Pollut Res Int. 2015;22(24):19870-19878. doi:10.1007/s11356-0155212-1

22. Gaudet HM, Christensen E, Conn B, Morrow S, Cressey L, Benoit J. Methylmercury promotes breast cancer cell proliferation. Toxicol Rep. 2018;5:579-584. doi:10.1016/j.toxrep.2018.05.002

23. McElroy JA, Shafer MM, Trentham-Dietz A, Hampton JM, Newcomb PA. Cadmium exposure and breast cancer risk. $J$ Natl Cancer Inst. 2006;98(12):869-873. doi:10.1093/jnci/djj233

24. Chen C, Sun S, Yuan JP, et al. Characteristics of breast cancer in Central China, literature review and comparison with USA. Breast. 2016;30:208-213. doi:10.1016/j.breast.2016.01.004

25. Chen XS, Nie XQ, Chen CM, et al. Weekly paclitaxel plus carboplatin is an effective nonanthracycline-containing regimen as neoadjuvant chemotherapy for breast cancer. Ann Oncol. 2010;21 (5):961-967. doi:10.1093/annonc/mdq041

26. Ohuchi N, Suzuki A, Sobue T, et al. Sensitivity and specificity of mammography and adjunctive ultrasonography to screen for breast cancer in the Japan Strategic Anti-cancer Randomized Trial (J-START): a randomised controlled trial. Lancet. 2016;387 (10016):341-348. doi:10.1016/S0140-6736(15)00774-6 
27. Leong SP, Shen ZZ, Liu TJ, et al. Is breast cancer the same disease in Asian and Western countries? World J Surg. 2010;34(10):2308-2324. doi:10.1007/s00268-010-0683-1

28. Wu Q, Ma G, Deng Y, et al. Prognostic value of ki-67 in patients with resected triple-negative breast cancer: a meta-analysis. Front Oncol. 2019;9:1068. doi:10.3389/fonc.2019.01068
29. Zhu X, Chen L, Huang B, et al. The prognostic and predictive potential of Ki-67 in triple-negative breast cancer. Sci Rep. 2020;10 (1):225. doi:10.1038/s41598-019-57094-3

\section{Publish your work in this journal}

Cancer Management and Research is an international, peer-reviewed open access journal focusing on cancer research and the optimal use of preventative and integrated treatment interventions to achieve improved outcomes, enhanced survival and quality of life for the cancer patient.
The manuscript management system is completely online and includes a very quick and fair peer-review system, which is all easy to use. Visit http://www.dovepress.com/testimonials.php to read real quotes from published authors. 